\title{
THE WORK OF A REFORMATORY FOR FEMALE INEBRIATES.
}

\author{
BY JAMES T. TRAVIS-GLEGG, \\ Chairman of the Lancashite Inebriates' Acts Board.
}

IN dealing with the question of inebriety, my claim to do so must rest merely on the experience $I$ have gained as Ghairman for the last five years of the Lancashire Inebriates' Acts Board in connection with its female criminal reformatory at Langho. I write, therefore, as a layman, but as a layman who has been brought into close touch with this most serious social evil, and one who has become increasingly impressed with the absolute importance not merely of checking the evil as it exists, but, if possible, of preventing its further growth.

Langho Reformatory was built under a special Act of Parliament, after the passing of the Inebriates Act, 1898, by the County Council and County Boroughs of Lancashire, and is managed by a joint board of representatives. It is built on the "villa" system, of which there are six, with a central administrative block and detached laundry and workrooms. It was opened in April, 1904, for some 140 inmates, but has now been altered and extended to accommodate 334. The Board has power to make arrangements with outside authorities to take women committed from their courts, and, in fact, an agreement does now exist with the London County Council, which sends a considerable number of women to Langho. The capital charges for interest and sinking fund are paid by precepts levied on the contributing authorities in Lancashire. The cost of maintenance is paid partly by the committing authorities and partly by a Treasury grant. In the case of women committed under Section I. of the Act, the whole cost of maintenance is paid by Government. In 1905, the first complete working year, the daily 
average number of inmates was eighty-three, and the cost of maintenance per head per week was nearly twenty-one shillings. The cost was naturally high, because the expense of administering such an institution with a small number of inmates is always relatively higher than with a larger number. In 1912 the daily average number of inmates was 250, and the cost of maintenance per head per week was $10 \mathrm{~s} .10 \mathrm{~d}$. The charge to the committing authorities is now 4s. 1d. per head per week as against 10s. $6 \mathrm{~d}$. in 1905. The maximum period of detention is three years, and the great majority of the women are committed for that period. They must, of course, be prosecuted under the Act, and must have had three previous convictions for drunkenness in twelve months before either committal or re-committal.

During the period of detention the women are kept at such useful work as they are able to perform. The laundry, rugmaking room, wood-chopping, and dressmaking departments do public work as well as work for the institution. On December 31, 1912, there were 280 women in the reformatory, whose occupations were as follows: House-work, 36 ; laundry, 36 ; mendingroom, 18 ; garden, 28 ; sick, 5 ; unfit for any work, 6 ; bakers, 2 ; kitchen, 22 ; rug-room, 61 ; wood-chopping, 8 ; dairy, 2 ; sewingroom, 33 ; painting, 9 ; dressmaking, 14 . The net proceeds from public work during 1912 amounted to 2 s. 2d. per head per week. This, of course, represents merely the balance after paying for materials. During their leisure hours, when they are in the common rooms of their respective villas, the women are allowed to do fancy work, etc., which is sold for them, and the proceeds added to the good conduct money they may have earned when they are discharged from the reformatory.

Although the reformatory is necessarily of prison character, the rigid discipline of a prison is relaxed as far as possible, and every effort is made to induce the women to regain, or, alas ! perhaps in most cases to gain for the first time, their self-respect. The Board has power to discharge on probation women who have served at least two-thirds of their sentence, and in some cases this has been done with successful results. The Board also tried for some years the experiment of allowing such women, as a reward for good conduct, to go out to houses in the district as daily charwomen, and though in the vast majority of cases the experiment worked well and was undoubtedly valuable in helping the women to gain confidence in themselves before being finally discharged, yet the opportunities afforded for smuggling contra- 
band into the reformatory and the temptation thrown in their way for obtaining intoxicants were so great that a few of the women fell, and the experiment has been stopped. Having dealt shortly with the reformatory, I may now deal with the material which is sent to us for reformation.

The Medical Director, in his first annual report, stated: " There is some evidence already that many of our inmates have started life with mental defect, and have become more defective owing to their long life of unrestrained drunkenness. Nearly all the inmates are confirmed in their habits, and morally degraded by the treatment to which they have been subjected for many years. All will undoubtedly benefit by their detention; but many of them, I fear, give evidence of having been sent too late for any reasonable probability of permanent results; but even with these we must bear in mind the benefit which society derives from their detention in a reformatory. By this means we prevent the irreformable from exercising unchecked their baneful influence over their young associates."

Nine years' experience amply confirms all that is contained in the above paragraph. The percentage of mentally defective women annually committed has never been less than fifty, and has usually been nearer sixty. In 1908 the percentage was 64.5 ; in $1909,59^{\circ} 9$; in 1910,52 ; in $1911,54^{\circ} 9$; in $1912,61^{\circ} 4$. In probably 10 per cent. of these defective women there is actual insanity. They are not as a rule mentally defective through drink, but are inebriates because they are mentally defective and are quite incapable of restraining that or any other passion which takes possession of them. They certainly are not criminals in the ordinary sense of the word, though their passions may occasionally lead them to commit some trivial crime.

The Medical Director, in his ninth annual report, states: "We cannot face these figures [relating to the percentage of mentally defective inmates] year after year as we have done now for eight years without being impressed with the close relationship that exists between the habitual inebriate and the feeble-minded, and so far as inmates of this reformatory are concerned, one might add, at first sight, the criminal. But inebriety is not a form of criminality; the inebriate is not a true criminal, and few real criminals are inebriates. The inebriate is a weakling, lacking the will power, determination, and ability to attain the higher branches in the profession of crime, where the dangerous 
criminals are found. They are criminal in the sense that they break the law, but their offences as a rule are trivial, and they do more harm to themselves than to the person or property of the community. They inflict great suffering and injury on their own families and relations, and when their anti-social qualities are brought out by drink, they are a nuisance and expense rather than a menace to society."

The question which suggests itself to those responsible for the management of the reformatory is whether it is possible to reform this mentally defective type of inebriate, and I think it should be admitted plainly and at once that it is not possible, or at any rate that the possibility is exceedingly remote. They are not amenable to any form of treatment or moral suasion, because they have not the will power necessary to assist the one nor the moral character to appreciate the other. Is it not, therefore, absolutely futile to arbitrarily determine the period of detention of an inebriate of this type? To say that after three years' detention at most she shall be turned out into society unchecked and uncontrolled till she has again been charged by the police four times in twelve months with an offence it is well known she cannot resist committing? To put it on the lowest ground, it is a gross waste of public money. Detention, if there is to be detention, should surely be permanent, or at any rate, as in the case of lunatics, indeterminate, and discretion allowed to those who have care of her to fix the time of her discharge. The same remarks apply to women of fifty-five years and upwards with a very large number of convictions for drunkenness against them. I know of a case where a woman of seventy years of age with 169 convictions for drunkenness against her has been committed for three years' detention.

So much for the mentally defective and aged inebriate. Of the remainder of the women it may be claimed, I think, there is some chance of reformation provided they are sent to the reformatory early enough in their careers. They may be classed mentally as " normal," though the very fact they are inebriates denotes a lack of will power; and the continual indulgence in drink, and, with them, its usual concomitant vice, will still further lessen their will power, and lower their mental capability. Here, again, it is most important that the period of detention should be indeterminate, and that discretion should be allowed to those in charge when to release on probation. In the early 
stages of inebriety the first period of detention might be short, but return to the reformatory must be immediate in case of relapse.

The only effective cure for inebriety is total abstinence, and that is just the most difficult cure to effect. Voluntary abstinence in face of temptation is wellnigh impossible. Enforced abstinence is possible either in an institution or by legalized control outside. I believe in some cases not too far gone the knowledge that further detention would follow a relapse would keep some of the women straight, though this does not apply to mentally defective women.

A judicious and effective system of after-care, which would prevent the sudden return to the old environment, and to the first and fatal celebration of the newly gained freedom would?, I believe, save many of the women from a relapse; but to be effective it must be compulsory, and to be judicious it must be carried out under official direction, with supervision strict enough on the one hand to insure proper control, and elastic enough on the othef hand to avoid the obnoxious principles of the ticket-ofleave system. Under the existing law no compulsory scheme of after-care is possible, and I fear voluntary effort is of little value because so few of the women will voluntarily submit to restraint after serving their period of detention, and, further, because a voluntary system must of necessity lack the means of enforcing penalties for non-compliance with its regulations. To allow an inebriate to return to her old environment at the end of her term, without any restriction and without any control, is simply asking for a relapse. I have known of many women who have relapsed who, I believe, quite honestly desired and intended to amend their ways on discharge. Some even have become quite nervous as the end of their term approached lest temptation should prove too strong for them; but the first taste, taken, perhaps, at the instigation of old friends, brings back the appetite and the craving, and the good resolutions are a thing of the past.

Then comes the next phase: Drink cannot be purchased without money. Experience shows us that comparatively few inebriate women are able to earn their own living by honest work in open competition in the labour market. The easiest way to earn it is on the streets. So the inebriate again becomes a danger to society, and in all likelihood propagates children who, in their probable environment, will inherit and hand down the disease 


\section{The British Journal of Inebriety}

from which their mother suffers. Unfortunately, statistics show that the birth-rate among degenerates of this class is considerably higher than the general rate, while the life-history of the inmates of the reformatory offers strong evidence of the hereditary nature of the disease. For instance, there have occasionally been two sisters and a mother and daughter serving their time together, and it is quite usual to find that a parent, brother, or sister of an inmate is or has been in a lunatic asylum.

I confess freely, so far as Langho Reformatory is concerned, we are at present fighting this social battle with our hands tied. Parliament has not time apparently to release our bonds. Yet in spite of this we are doing good work and achieving better results than might be expected from such an uneven contest.

In August, 1910, when we endeavoured to obtain a report of all the women who had passed through the reformatory to that date, after eliminating all the cases we admitted to be irreformabie -some 50 per cent. of the whole-we found that of the remainder, some 47 per cent., had not relapsed, or at any rate had not again got into the hands of the police.

As a piece of outside and impartial evidence as to the work of the reformatory, I should like to quote from the report of Mr. Dunning, late Head Constable of Liverpool, to his Watch Committee in 1908. He writes: "The truth is that a great many of the women sent to Langho are incurable, being either mental degenerates from birth, or so far gone in the drink habit as to be incapable of the mental effort necessary for the prolonged abstention from drink. If the provisions of the Act were widened so as to sweep in more of the curable cases, the reformatory would, I believe, succeed with many of them, as I can imagine no treatment more likely to do so than that which is provided there. But the good done with incurable cases must not be overlooked; they are getting the treatment which is meant for others, and until some rational way of dealing with them is provided, it is a very good thing that it is so. One has only to see one of them in the dock at Liverpool-dirty, drinksodden, foul-mouthed, and scarcely human-and to see the same woman a few months later at Langho clean, sober, and at work, to realize what an asylum the place is for her, and to regret that, instead of being kept there, she will be thrown again on the streets of Liverpool as a sacrifice to the fetish of individual 
liberty, and that the only hope for her will be to get through the weary round of four more convictions as soon as possible, and qualify for another period of peace at Langho."

Inebriety is only one phase of the general question of degeneracy. It is a result, I suppose, of our advanced stage of civilization, and of our artificial mode of existence. Mother Nature never forgets an injury. She always revenges herself in the long-run on those who either individually or collectively habitually outrage her laws. One of her first laws is "the survival of the fittest." Under our civilization that is considered a cruel and barbarous law. Certainly we allow the fittest to survive, though we take very little care to keep them fit. It is the unfit we look after.

We never nowadays think of tackling social problems till they have become social evils, and even social evils have to give place to political exigency. Nothing, to my mind, illustrates this more clearly than the withdrawal by the Government last session of the Mental Deficiency and Inebriates Bills. Both of these Bills were the result of recommendations of ad hoc Parliamentary Committees; both are urgently needed in the interests of the community ; both were non-party, and largely non-controversial measures ; yet both were jettisoned in favour of measures which, whatever their political importance may be, are certainly not comparable to them as regards the amelioration of social evils. All that remains of the really useful proposals contained in these two Bills is the emasculated measure introduced this session as a Mental Deficiency Bill. The long-promised Inebriates Bill has disappeared altogether. 